\title{
REVIEW
}

\section{Pathophysiology and Complications during Extracorporeal Circulation}

\author{
Shinji Kawahito, MD, PhD¹), Tomohiro Soga, MD, $\mathrm{PhD}^{1)}$, Shusuke Yagi, MD, PhD¹, Naoji Mita, MD, PhD²), \\ Kazumi Takaishi, DDS, $\mathrm{PhD}^{3)}$, Hiroyuki Kinoshita, MD, $\mathrm{PhD}^{4)}$, Tetsuya Kitagawa, MD, $\mathrm{PhD}^{5}$, \\ and Hiroshi Kitahata, MD, $\mathrm{PhD}^{3)}$ \\ ${ }^{1)}$ Department of Community Medicine and Human Resource Development, Tokushima University Graduate School of Biomedical Sciences, \\ Tokushima, Japan, ${ }^{2}$ Department of Anesthesiology, Tokushima University Graduate School of Biomedical Sciences, Tokushima, Japan, \\ ${ }^{3)}$ Department of Dental Anesthesiology, Tokushima University Graduate School of Biomedical Sciences, Tokushima, Japan, ${ }^{4)}$ Department of \\ Anesthesiology, Seirei Mikatahara General Hospital, Shizuoka, Japan, ${ }^{5)}$ Department of Cardiovascular Surgery, Shikoku Central Hospital of \\ the Mutual Aid Association of Public School Teachers, Ehime, Japan
}

\begin{abstract}
Extracorporeal circulation, unlike pulsatile flow based on the beating heart, is the non-pulsatile flow through a blood pump, and the systemic circulation falls into non-physiological conditions. The living body shows various reactions to extracorporeal circulation. The pathophysiology of extracorporeal circulation includes changes in hemodynamics, coagulation, fibrinolysis, acid-base equilibrium, electrolytes, incretion, metabolism, and immune system. With advances in extracorporeal circulation technology, operability has been dramatically improved and safety has rapidly advanced as well. However, there are specific complications with extracorporeal circulation. We need to have a good knowledge of the pathophysiology and complications during extracorporeal circulation, as well as each component of the extracorporeal circulation system. J. Med. Invest. 67: 229-235, August, 2020
\end{abstract}

Keywords : Extracorporeal circulation, Cardiopulmonary bypass, Pathophysiology, Complication

\section{INTRODUCTION}

Since the success of open heart surgery with extracorporeal circulation (ECC) using a cardiopulmonary bypass (CPB) system by Gibbons in 1953, ECC technologies have rapidly advanced through the untiring efforts of many people (1). Currently, ECC is neither a special treatment method nor an auxiliary means, and is currently used as an indispensable medical technology for daily medical care in many facilities. In particular, cardiovascular surgery and CPB machines have been developed in close cooperation.

Although the roles and responsibilities of an anesthesiologist during the use of a CPB system vary with different facilities, they are generally in charge of anesthesia, respiration and circulation, anticoagulant, blood transfusion, and drug administration. They are also responsible for comprehensively cooperating in the safe implementation of ECC. The effects of the CPB system on an organism are enormous, and the knowledge associated with ECC is quite extensive (2). We need to have a good knowledge of ECC and the vital reactions (pathophysiology during ECC) as well as each component of the CPB system. The pathophysiology of ECC includes changes in hemodynamics, coagulation, fibrinolysis, acid-base equilibrium, electrolytes, incretion, metabolism, and immune system. In this report, we provide an outline of the pathophysiology and complications of ECC centering on the CPB during cardiovascular surgery.

Received for publication June 19, 2020 ; accepted July 13, 2020.

Address correspondence and reprint requests to Dr. Shinji Kawahito, Department of Community Medicine and Human Resource Development, Tokushima University Graduate school of Biomedical Sciences 3-18-15, Kuramoto, Tokushima 770-8503, Japan and Fax : +81-88633-7182.

\section{PATHOPHYSIOLOGY OF EXTRACORPOREAL CIRCULATION}

ECC has been further developed to expand its adaptations from CPB during cardiovascular surgery to ventricular assist device (VAD) to assist cardiac function, extracorporeal membrane oxygenation (ECMO) to assist respiratory function, percutaneous cardiopulmonary support (PCPS) used mainly in the emergency field, hemodialysis to support renal function and blood purification to remove various toxic substances etc. (3). There are new treatments for respiration, circulation, and metabolism available due to advances in ECC equipment such as artificial lungs, blood pumps, filtration films, coating technology, and device miniaturization. The non-physiological conditions found during ECC are shown in Table 1, and vital reactions specific to ECC may occur.

Table 1. Non-physiological situation due to the extracorporeal circulation

- Nonpulsatile flow circulation (roller pump, centrifugal pump)

- Blood flow disappearance of pulmonary circuit

- Long-time contact with an artificial substance

- Physical damage of the blood (pump, artificial lung)

Hemodilution

Hypothermia

-Artificial adjustment of gas exchange, hemodilution, and temperature

\section{Changes in coagulation and the fibrinolysis system :}

During ECC, the blood that is placed in various non-physiological environments, including blood dilution and contact with foreign matter, shows coagulation system changes. Coagulation has an extrinsic system beginning with the VIII factor and an 
endogenous system beginning with the XII factor; ultimately, insoluble fibrin is formed by the cascade reaction of coagulation factors being activated one after another. The blood coagulation in ECC is induced by the blood-foreign surface reaction that occurs when blood is in contact with the circuit inner surface. During ECC, the coagulating system is in a state of suppression due to the use of heparin as an anticoagulant, but the enhancement in various thrombin generation markers is observed. In addition, during ECC, fibrinolytic system variation is observed as well as coagulation system activation (4). Moreover, a report already showed that the enhancement of the fibrinolytic system was observed during ECC using heparin.

\section{Changes in acid-base equilibrium :}

The acid-base equilibrium during ECC is mainly influenced by the perfused blood flow of ECC and the performance of the oxygenator. During ECC, the living body is placed in non-physiological environments such as hemodilution, hypothermia, and non-pulsatile flow, resulting in the decreased oxygen-carrying capacity of the blood due to blood flow stagnation in the peripheral circulation, anemia, and the left shift of the oxygen dissociation curve. Furthermore, metabolic acidosis is likely to be caused by increased lactate and pyruvate. In particular, the progress in metabolic acidosis is remarkable when the perfused blood flow is insufficient.

\section{Changes in electrolytes:}

In general, it is known that hypokalemia occurs during ECC, and the intracellular shift of potassium in the extracellular fluid moving into the cell is considered the main cause (5). In hypokalemia, the generation frequency of supraventricular and ventricular extrasystoles increases, and the atrioventricular and intraventricular conductions are likely to be disturbed. Thus, the monitoring of the serum potassium value during ECC is very important in order to prevent arrhythmias in the perioperative period (6). It is known that sodium, chlorine, and calcium during ECC can be reduced as well.

\section{Endocrinologic changes :}

The living body increases various stresses during ECC and a change is expected in the endocrine system. With ECC introduction, the anterior pituitary hormone generally shows an upward trend. Gonadotropin [luteotrophic hormone (LH), follicle-stimulating hormone (FSH), and prolactin] increases and adenocorticotropic hormone (ACTH) rises with ECC introduction, but shows a low value during ECC (7). The growth hormone also rises. Because various non-physiological stresses also increase during ECC for catecholamine, secretions of both epinephrine and norepinephrine are known to increase (Fig. 1) (8). Some increases in cathecholamine concentrations during and after CPB may be unavoidable with current anesthetic and surgical techniques ; nevertheless, higher doses of opioids, inhaled general anesthetics, and epidural anesthesia can limit this increase. Vasopressin also significantly increases like catecholamine and the high value lasts even after operation (9).

A drop in renal perfusion pressure, such as during hyponatremia, becomes the stimulation during ECC and enhanced activity of the renin angiotensin aldosterone system is observed (10). It is necessary to note that activation of the renin angiotensin aldosterone system participates in the balance of the postoperative electrolyte and peripheral artery resistance and becomes a factor in high blood pressure and low cardiac function. The natriuretic peptide family is known to rise with evolutionary time during ECC and present a high value at end of the ECC.

Hyperglycemia during ECC is mainly explained by insufficient insulin secretion. In addition, peripheral vascular resistance is high during ECC, insufficient peripheral circulation prevents glucose utilization in cells, and glycolytic enzymes are inhibited by hypothermia. Increase in free fatty acid due to rises in catecholamine, growth hormone, ACTH, and thyroid-stimulating hormone (TSH) during ECC are known as lipid metabolism. In contrast, triglycerides decrease (11). For adrenal cortical hormone, increase in cortisol is known to be more remarkable than that in general surgery due to various stresses during ECC. In addition, the promoted secretion of cortisol with ACTH is not seen at the peak of cortisol, and it has been reported to be in a state of adrenal cortex hyperfunction (12). For thyroid hormone, it is known that both triiodothyronine (T3) and free T3 significantly decrease during ECC, and the thyroxine (T4) level does not fluctuate, although free T4 increases. As T3 is a more important thyroid hormone more than T4, hypothyroidism occurs during ECC (Fig. 2) (13).
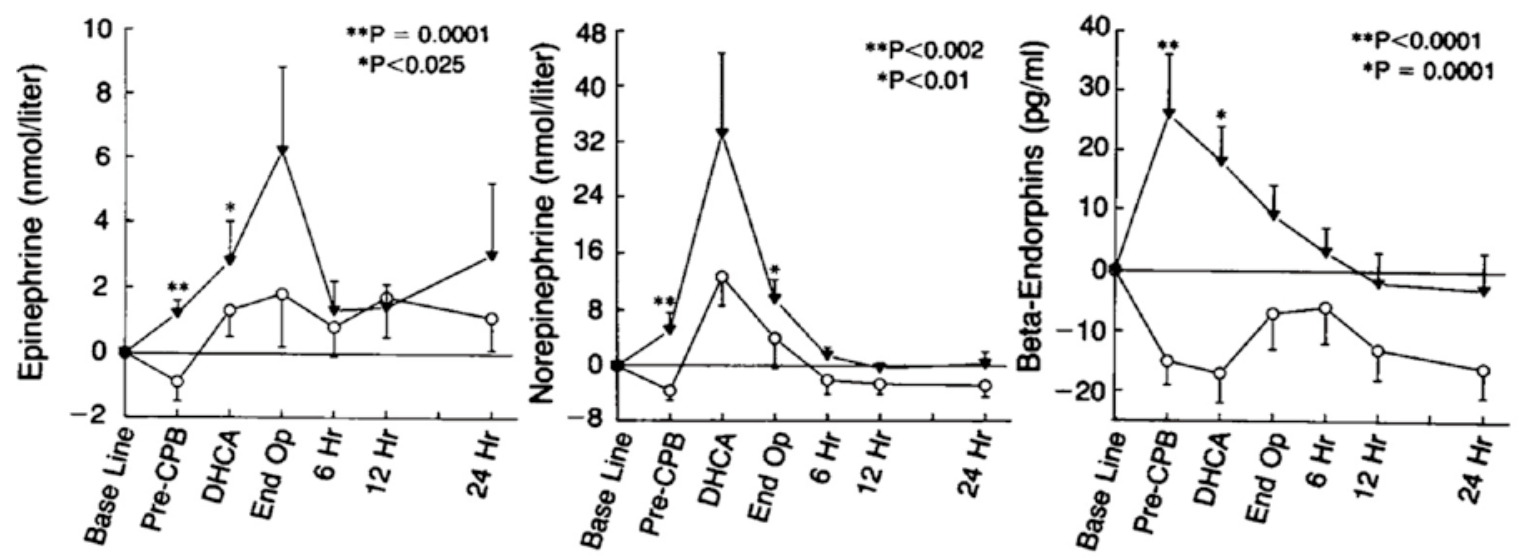

Time Point

Fig 1. Perioperative changes in plasma epinephrine and norepinephrine concentrations and plasma beta-endorphin immunoreactivity in neonates undergoing cardiac surgery with halothane-morphine $(\mathbf{\nabla}, n=15)$ or high-dose sufentanil $(\bigcirc, n=30)$ anesthesia. Pre-CPB denotes measurement before cardiopulmonary bypass; DHCA denotes measurement after deep hypothermic circulatory arrest ; measurements were also made at end of operation (End Op), and 6, 12, and 24 hours (Hr) after operation. P values were determined with the Mann-Whitney U test. Data are shown as the mean \pm the standard error of the mean.

(From Ref. 8 Anand KJS, et al. N Engl J Med 326 : 1-9, 1992) 


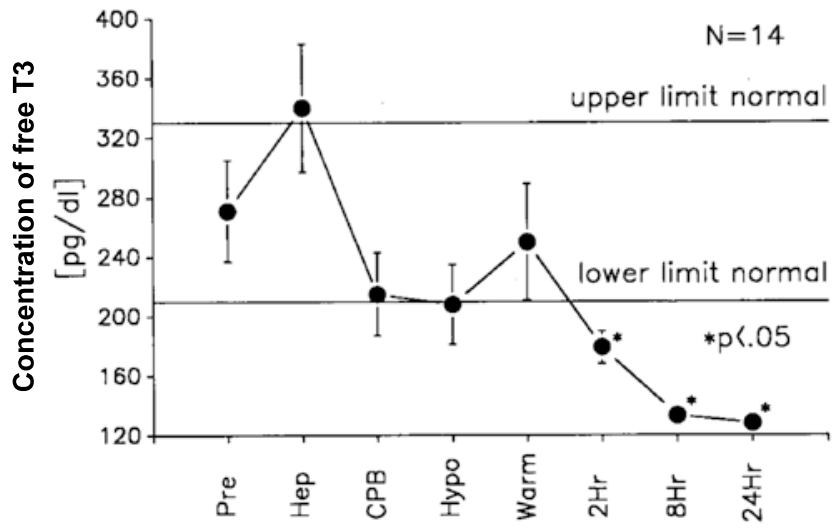

Fig 2. Response of free T3 concentration to cardiovascular surgery in 14 patients.

T3 declined during cardiopulmonary bypass (CPB) and then declined further during the first 24 hours after surgery. Concentrations of free T3 during cardiac surgery in the 14 patients were measured preoperatively (Pre), after administration of heparin (Hep), after initiation of $\mathrm{CPB}$, at the nadir of hypothermia (Hypo), after rewarming (Warm), and at 2, 8, and 24 hours after CPB. Statistical comparisons were made between the preoperative and subsequent measurements. Data are shown as the mean \pm the standard error of the mean.

(From Ref. 13 Holland FW 2nd, et al. Ann Thorac Surg 52 : 46-50, 1991)

\section{Changes in the immune system :}

ECC generally suppresses immune function, but may partially activate it. In addition, humoral and cellular immunity induce different reactions with various fluctuations, complicating their actions. The fluctuations in the humoral immunity include decreases in immunoglobulin levels, elevated complement activity due to contact between blood and artificial materials, consumption of blood complements, and increases in almost all cytokines. Neutrophils migrate, cohere, and deposit in the vascular bed of the lungs and kidney due to activation of the complement system, and lung and kidney complications may be caused by polymorph elastase released by neutrophils (14). It is considered that B lymphocytes and T lymphocytes generally decrease during ECC due to a change in cell-mediated immunity (15).

\section{COMPLICATIONS WITH EXTRACORPOREAL CIRCULATION}

Complications due to ECC include : (1) bleeding, (2) embolism, (3) anaphylactic reaction, (4) those associated with cannulation, (5) blood damage and hemolysis, and (6) hyperglycemia. Based on recent studies, it is highly improbable that complications due to ECC can be eliminated in routine clinical practice. However, an awareness of the factors responsible for their etiology may allow surgical teams to minimize the number of complications and their outcomes.

\section{Bleeding :}

The bleeding complications during cardiovascular surgery associated with CPB are related to pre-existing coagulation deficiencies, heparin, activation of platelets, as well as fibrinolysis. Patients with pre-existing coagulation deficiencies are detected and treated preoperatively. CPB dilutes soluble coagulation factors and reduces factor V and VIII to concentrations below those expected from dilution (16), but bleeding rarely, if ever, occurs from this cause. The most common cause of heparin-related bleeding, after CPB, is inadequate neutralization of heparin with protamine. Heparin rebound describes the increase in bleeding 1 to 3 hours after surgery attributed to the release of heparin bound to endothelial cells and macrophages after protamine has been cleaned from the circulation (17). Causes of bleeding related to coagulation and the fibrinolysis system are described above.

\section{Embolization :}

It is generally accepted that postoperative cerebral dysfunction after the use of CPB is largely attributable to microembolism and/or hypoperfusion (18). The brain has been the focus of many studies evaluating adverse surgical outcomes after CPB, which has been facilitated by a large number of available tests that have the capacity to assess cerebral damage. Reports indicate that the incidence of clinically obvious stroke after CPB procedures is $1 \%$ to $5 \%$, while magnetic resonance imaging studies suggest that a new cerebral infarct may occur in as many as $30 \%$ of the same patients $(19,20)$. Additionally, histologic studies have also shown embolic materials in the kidneys, heart, liver, lungs, and spleen after CPB. Emboli have traditionally been classified into three categories : biologic, foreign material, and gaseous, each of which has the ability to distribute into and obstruct arterial vessels throughout the body.

Biologic products include microthrombi containing fibrin/ fibrinogen, lipid materials, proteins, bones, and muscle fragments. Platelets, neutrophils, and red cell aggregates are also commonly observed during and after CPB. Fat emboli may be observed directly using microscopy (Fig. 3) or can be inferred from increases in serum concentrations of total lipids, free fatty acids, triglycerides, or lipases. It has been estimated that two thirds of the fat emboli developed within a CPB circuit enter through cardiotomy suction (21).

Foreign materials can be present in multiple components of the CPB circuit and in the priming solutions used for bypass, or they may arise from the interaction of various components either pre-bypass (e.g., pump-tubing interaction) or while on CPB. These foreign bodies may arise during manufacturing or assembly of circuit components. A variety of different materials have been found in the CPB circuit, including cotton fibers, plastic, or metal particles (22), antifoam, and filter and tubing materials. Similarly, the operative field can be a source of foreign materials including talc, bone wax, bone fragments, muscle fragments, microfibrillar collagen, calcium particles, and surgical thread (23).

Gross air embolism is now uncommon because of safeguards and changes in clinical practices that have ensued from identification of their most frequent causes. It is likely that the most frequent cause has been perfusion inattention leading to the emptying of the venous reservoir and concomitant pumping of air into the patient. Other causes include introduction of air into the aortic root from the cardioplegia delivery tubing and cannula, cardiac contractions before intracardiac de-airing is complete, and accidental reversal of flow in the left ventricular venting system (24). Willcox et al. demonstrated that vacuum-assisted venous drainage augmented the rate and amount of air entrainment into the circuit by almost 10 -fold when compared with gravity venous drainage (Fig. 4) (25). Iatrogenic air embolism continues to occur during $\mathrm{CPB}$, although the incidence has been greatly reduced.

\section{Anaphylactic reaction :}

There are a number of effects of activation of the complement system. First, a number of proteins, most notably the anaphylatoxins, $\mathrm{C} 3 \mathrm{a}, \mathrm{C} 4 \mathrm{a}$, and $\mathrm{C} 5 \mathrm{a}$, are produced. These molecules act 

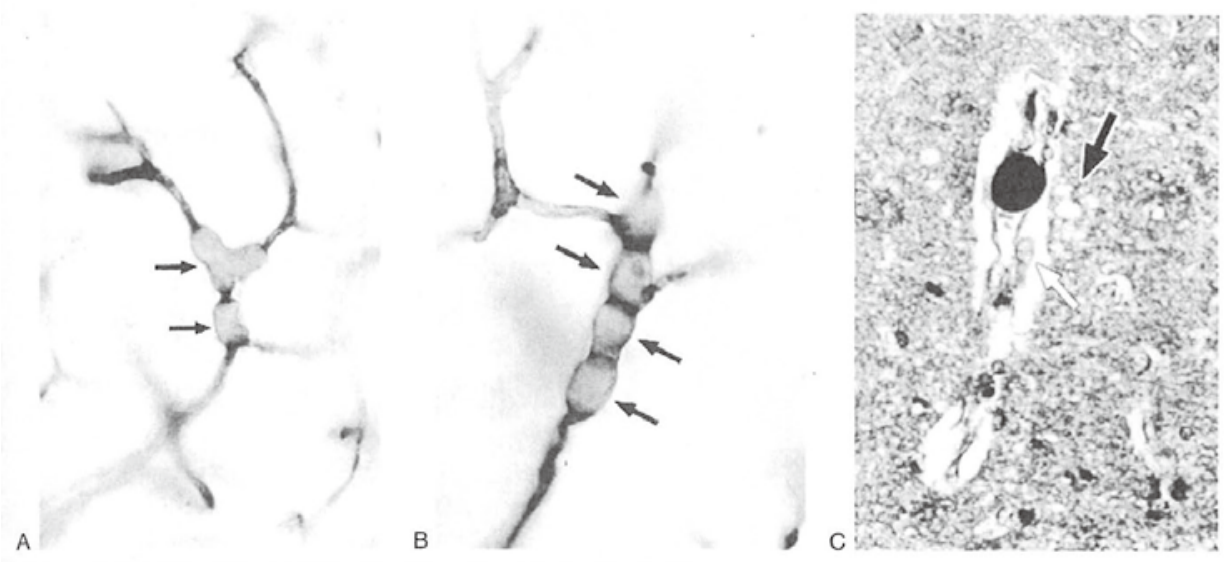

Fig 3. High magnification photomicrographs of microlipid emboli from patients who died after cardiopulmonary bypass.

Original magnification $\times 50$. (A) and (B) : Microemboli at bifurcation points (arrows) in $100 \mu \mathrm{m}$-thick celloidin sections with alkaline phosphatase microvascular staining. (C) : A microembolus (paraffin-embedded, $5 \mu \mathrm{m}$ thick osmium-fixed section) stained black with osmium indicates that it is a lipid. Swollen astrocytic endfeet (white arrow) and vacuolization in the adjacent neutrophil (black arrow) indicate tissue injury.

(From Ref. 2 Gravlee GP, et al. Cardiopulmonary bypass : principles and practice, third edition, Lippincott Williams \& Wilkins, Philadelphia, 2008)

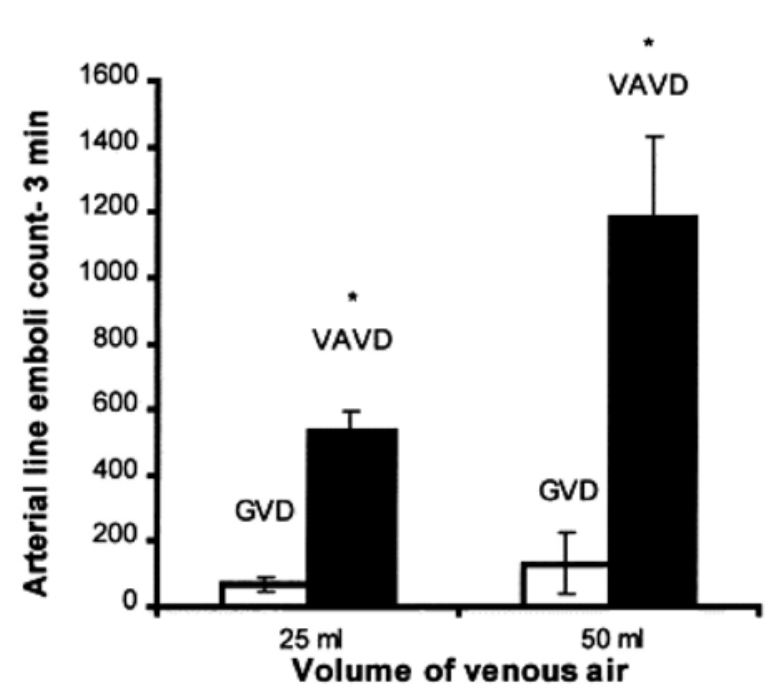

Fig 4. The mean arterial-line emboli count after entrainment of 25 and $50 \mathrm{~mL}$ of venous air downstream from a $40-\mu \mathrm{m}$ arterial line filter under gravity venous drainage (GVD) and $-60 \mathrm{mmHg}$ vacuumassisted venous drainage (VAVD).

For both volumes of entrained air, an almost tenfold increase in arterial line emboli count was seen under VAVD. Data are shown as the mean \pm the standard deviation. $* p<0.0001$ compared with GVD. (From Ref. 25 Willcox TW, et al. Ann Thorac Surg 68:1285-1289, 1999)

through receptors on mast cells and basophils, leading to their degranulation and the release of a wide range of inflammatory mediators (including histamine). They also act directly on smooth muscle and endothelium, leading to muscle contraction and an increase in vascular permeability. In addition, C5a acts as a chemotactic and activating agent for neutrophils and other myeloid cells, leading to both their recruitment and release of lysosomal enzymes, reactive oxygen species, and other inflammatory mediators (26).
Activation of the complement system is observed during or shortly after CPB, mainly through the alternative pathway, and is induced by blood contact with the non-physiologic surface, and later by ischemia reperfusion. Protamine administration and the subsequent formation of heparin-protamine complexes can further activate the complement system through the classical pathway. This, in turn, mediates cellular damage, endothelial cell and leukocyte activation, histamine release, increased vascular permeability, and generalized inflammatory response (27). Previously, we reported a case of severe bronchospasm induced by CPB (28).

\section{Complications associated with cannulation :}

The surgical procedure is the most important source of macroemboli and microemboli that produce lasting damage to the central nervous system. Artery dissociation with cannulation, false lumen blood transmission, and vessel stenosis (29) are complications to be noted. Cannulation and manipulation of the ascending aorta, particularly in patients with soft atheromatous material in the aorta, are a major source of atheromatous macroemboli (30). Microemboli are also produced during cardiac surgery and may cause postoperative neuropsychologic deficits in proportion to the number of emboli. Surgical steps, particularly aortic cannulation and manipulation of either the heart or the aorta, are correlated with the highest production of microemboli.

\section{Blood damage and hemolysis :}

Hemolysis occurs due to contact between blood cells and foreign substances, and pressure gradients. Serum free hemoglobin is measured as a hemolytic index (31). Total hemolysis due to a centrifugal pump, membrane oxygenator, and cannula is equivalent to the hemolysis during ECC, although the hemolysis due to a membrane oxygenator accounts for a large portion. For longterm use as PCPS/ECMO, those causing less hemolysis should be selected (32-34).

\section{Hyperglycemia :}

It is generally easy for a patient to become hyperglycemic during surgery (35), but they may often be in the state of significant hyperglycemia due to restrained secretion of insulin (36) 
(hypoperfusion of the pancreas, restrained reaction of pancreatic $\beta$ cells due to hypothermia, and excessive secretion of insulin antagonistic hormones). This restraint is an obstacle for glucose use in cells due to peripheral hypoperfusion and inhibition of glycolytic enzymes caused by the hypothermia during cardiovascular surgery, particularly the use of $\mathrm{CPB}$ (37). One case of continuous blood glucose monitoring during cardiovascular surgery is shown in Fig. 5 (38). The blood glucose level gradually rises with the start of $\mathrm{CPB}$ and then rapidly rises by completion of $\mathrm{CPB}$ and aortic clamp. The level may decrease after $\mathrm{CPB}$, but there are many cases where a hyperglycemic state continues. The change of blood glucose level associated with CPB is sudden and is hard to manage through administration of intermittent insulin glucose with a sliding scale. Using a continuous blood glucose monitoring and control system (artificial pancreas : STG-55 from Nikkiso Corporation), studies have performed blood glucose control during CPB (Fig. 6) (38-40). The blood glucose level suddenly showed an upward trend after the start of CPB, but was controlled to around $150 \mathrm{mg} / \mathrm{dL}$ through appropriate insulin administration. In addition, the blood glucose level showed a tendency to drop by the end of the CPB machine, but hypoglycemia was avoided through appropriate glucose administration. Strict

\section{BS}

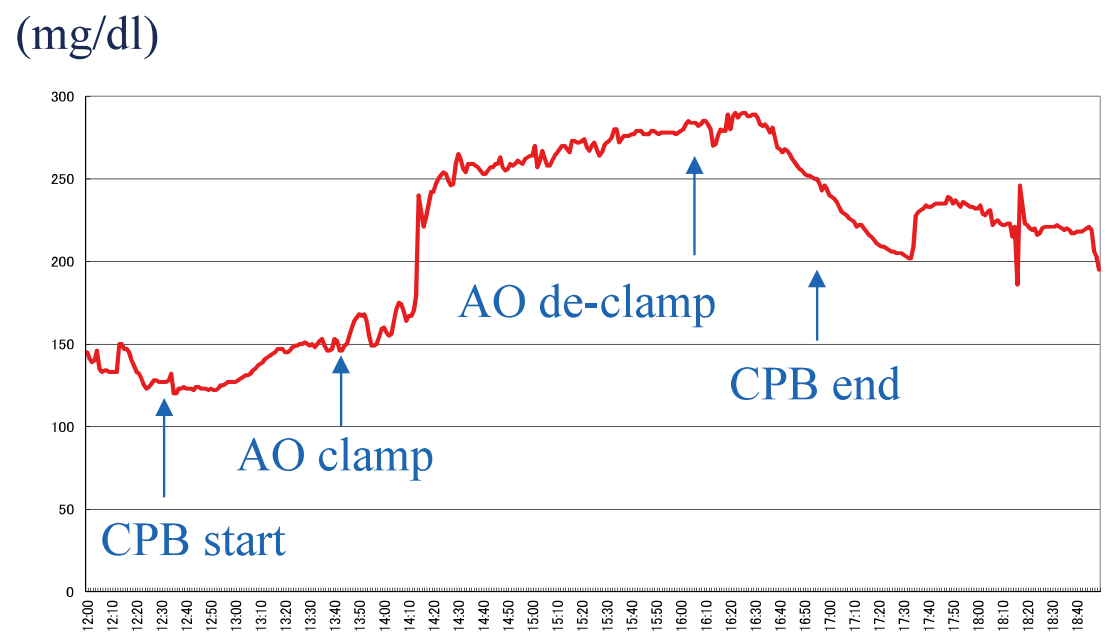

Fig 5. Continuous blood glucose monitoring during cardiovascular surgery with cardiopulmonary bypass. Significant hyperglycemia occurred during cardiopulmonary bypass after initiation of cardiopulmonary bypass using an aortic clamp ; the blood glucose level increased markedly to around $300 \mathrm{mg} / \mathrm{dL}$. BS, blood sugar ; CPB, cardiopulmonary bypass ; AO, aorta

(From Ref. 38 Kawahito S, et al. J Med Invest 57 : 191-2004, 2010)

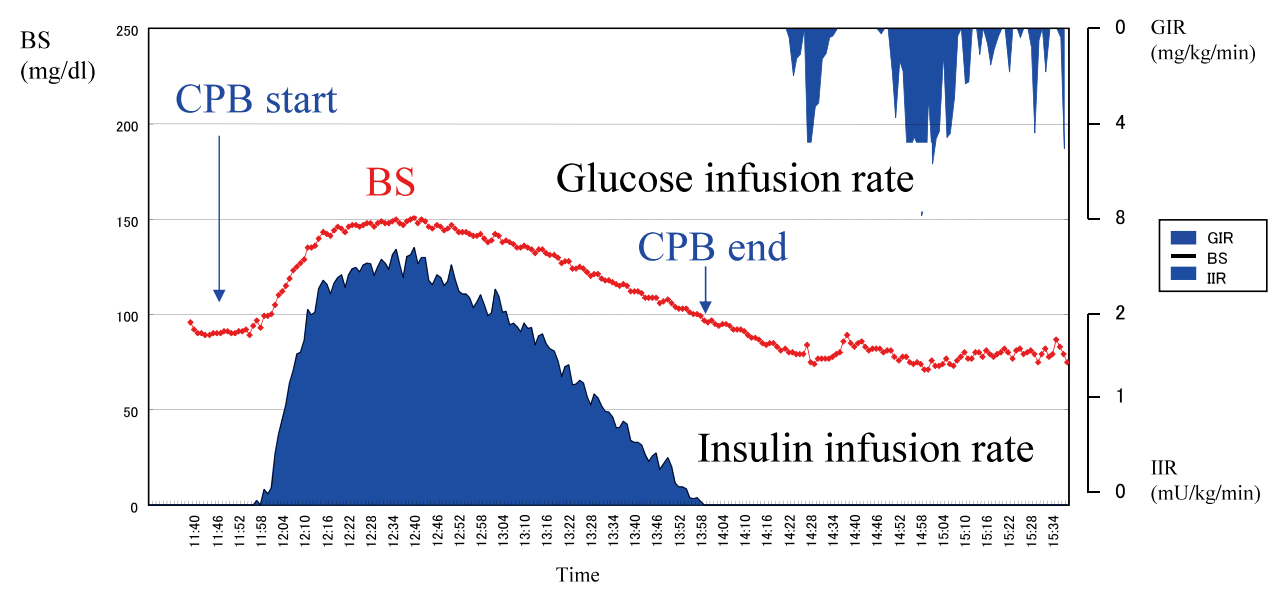

Fig 6. Intensive insulin therapy during cardiovascular surgery using artificial endocrine pancreas.

The blood glucose level suddenly increased after the initiation of cardiopulmonary bypass, but only to a maximum of $150 \mathrm{mg} / \mathrm{dL}$, and the level was then controlled by appropriate insulin administration. After termination of the cardiopulmonary bypass, the blood glucose level began to decrease, but hypoglycemia was avoided through appropriate glucose administration.

$\mathrm{BS}$, blood sugar ; CPB, cardiopulmonary bypass ; GIR, glucose infusion rate ; IIR, insulin infusion rate

(From Ref. 38 Kawahito S, et al. J Med Invest 57 : 191-2004, 2010) 
blood glucose control using an artificial endocrine pancreas may improve outcomes of the patients undergoing cardiovascular surgery.

\section{CONCLUSION}

Despite extensive knowledge of ECC, anesthesiologists should further understand the pathophysiology and complications during ECC to respond flexibly to recent advances in ECC.

\section{DISCLOSURE}

None of the authors have any conflict of interest to declare.

\section{REFERENCES}

1. Nosé Y, Motomura T, Kawahito S: The ICMT PUBLICATION ON ARTIFICIAL ORGANS Volume II : OXYGENATOR -Artificial Lung- Past, Present, and Future. ICAOT press, Ohio, 2001

2. Gravlee GP, Davis RF, Stammers AH, Ungerleider RM : Cardiopulmonary bypass : principles and practice, third edition, Lippincott Williams \& Wilkins, Philadelphia, 2008

3. Kawahito S, Kitahata H, Kitagawa T, Oshita S, Nosé $\mathrm{Y}$ : Non-cardiac surgery applications of extracorporeal circulation. J Med Invest 54 : 200-210, 2007

4. Hunt BJ, Parratt RN, Segal HC, Sheikh S, Killis P, Yacoub $\mathrm{M}$ : Activation of coagulation and fibrinolysis during cardiothoracic operations. Ann Thorac Surg 65 : 712-718, 1998

5. Morgan DB, Mearns AJ, Burkinshaw L: The potassium status of patients prior to open-heart surgery. J Thorac Cardiovasc Surg 76 : 673-677, 1978

6. Abe T, Nagata Y, Yoshioka K, Iyomasa Y : Hypopotassemia following open heart surgery by cardiopulmonary bypass. $\mathrm{J}$ Cardiovasc Surg 18: 411-419, 1977

7. Taylor KM, Bremner WF, Gray CE, Ratcliffe JG, Bain $\mathrm{WH}$ : Anterior pituitary function during cardiopulmonary bypass. Br J Surg 63 : 161-162, 1976

8. Anand KJS, Hickey PR : Halothane-morphine comparted with high-dose sufentanil for anesthesia and postoperative analgesia in neonatal cardiac surgery. N Engl $\mathrm{J}$ Med $326: 1-9,1992$

9. Kaul TK, Swaminathan R, Chatrath RR, Watson DA : Vasoactive pressure hormones during and after cardiopulmonary bypass. Int J Artif Organs 13 : 293-299, 1990

10. Nagaoka $H$, Innami $R$, Arai $H$ : Effects of pulsatile cardiopulmonary bypass on the renin-angiotensin-aldosterone system following open heart surgery. Jpn J Surg 18 : 390396, 1988

11. Arrants JE, Gadsden RH, Huggins MB, Lee WH Jr : Effects of extracorporeal circulation upon blood lipids. Ann Thorac Surg 15 : 230-242, 1973

12. Taylor KM, Jones JV, Walker MS, Rao S, Bain WH : The cortisol response during heart-lung bypass. Circulation 54 : 20-25, 1976

13. Holland FW 2nd, Brown PS Jr, Weintraub BD, Clark RE : Cardiopulmonary bypass and thyroid function : a "euthyroid sick syndrome”. Ann Thorac Surg 52 : 46-50, 1991

14. Kirklin JK, Westaby S, Blackstone EH, Kirklin JW, Chenoweth DE, Pacifico AD : Complement and the damaging effects of cardiopulmonary bypass. J Thorac Cardiovasc Surg $86: 845-857,1983$
15. Tajima K, Yamamoto F, Kawazoe K, Nakatani I, Sakai H, Abe T, Kawashima Y : Cardiopulmonary bypass and cellular immunity : changes in lymphocyte subsets and natural killer cell activity. Ann Thorac Surg 55 : 625-630, 1993

16. Harker LA, Malpass TW, Branson HE, Hessel EA 2nd, Slichter SJ : Mechanism of abnormal bleeding in patients undergoing cardiopulmonary bypass : acquired transient platelet dysfunction associated with selective alpha granule release. Blood $56: 824-834,1980$

17. Pifarrè R, Babka R, Sullivan HJ, Montoya A, Bakhos M, El-Etr A : Management of postoperative heparin rebound following cardiopulmonary bypass. J Thorac Cardiovasc Surg 81 : 378-381, 1981

18. Kurusz M, Butler BD, Katz J, Conti VR : Air embolism during cardiopulmonary bypass. Perfusion $10: 361-391$, 1995

19. Goto T, Baba T, Honma K, Shibata Y, Arai Y, Uozumi H, Okuda T: Magnetic resonance imaging findings and postoperative neurologic dysfunction in elderly patients undergoing coronary artery bypass grafting. Ann Thorac Surg $72: 137-142,2001$

20. Wityk RJ, Restrepo L : Cardiac surgery and magnetic resonance imaging of the brain. Arch Neurol 59 : 1074-1076, 2002

21. Clarke RE, Margraf HW, Beauchamp RA : Fat and solid filtration in clinical perfusion. Surgery $77: 216-224,1975$

22. Takano T, Nakata K, Schulte-Eistrup S, Kawahito S, Glueck J, Clarke IC, Williams PA, Maeda T, Nonaka K, Linneweber J, Yoshikawa M, Fujisawa A, Makinouchi K, Yokokawa M, Nosè Y : Particle released from the Gyro C1E3 during simulated extracorporeal circulation. Artif Organs $24: 446-449,2000$

23. Merkle F, Bottcher W, Hetzer R : Prebypass filtration of cardiopulmonary bypass circuits : an outdated technique? Perfusion 18: 81-88, 2003

24. Kurusz M, Butler BD : Bubbles and bypass : an update. Perfusion 19: S49-S55, 2004

25. Willcox TW, Mitchell SJ, Gorman DF : Venous air in the bypass circuit : a source of arterial line emboli exacerbated by vacuum-assisted drainage. Ann Thorac Surg 68:12851289,1999

26. Gerard C, Gerard NP : C5a anaphylatoxin and its seven transmembrane-segment receptor. Annu Rev Immunol $12: 775-808,1994$

27. Miller BE, Levy JH : The inflammatory response to cardiopulmonary bypass. J Cardiothorac Vasc Anesth 11 : 355366, 1997

28. Kawahito S, Kitahata H, Tanaka K, Nozaki J, Oshita $\mathrm{S}$ : Bronchospasm induced by cardiopulmonary bypass. Ann Thorac Cardiovasc Surg $7:$ 49-51, 2001

29. Nitta K, Kawahito S, Kitahata H, Nozaki J, Katayama T, Oshita S : Two unusual complications associated with cardiopulmonary bypass for pediatric cardiac surgery detected by transesophageal echocardiography after decannulation. Paediatr Anaesth 18: 325-329, 2008

30. Wareing TH, Davila-Roman VG, Brazilai B, Murphy SF, Kouchoukos NT : Management of the severely atherosclerotic ascending aorta during cardiac operations : a strategy for detection and treatment. J Thorac Cardiovasc Surg 103: 453-462, 1992

31. Koller T Jr, Hawrylenko A : Contribution to the in vitro testing of pumps for extracorporeal circulation. J Thorac Cardiovasc Surg $54: 22-29,1967$

32. Kawahito S, Maeda T, Yoshikawa M, Takano T, Nonaka K, Linneweber J, Minami M, Motomura T, Ichikawa S, Glueck J, Nosè Y : Blood trauma induced by clinically accepted 
oxygenators. ASAIO Journal $47: 492-495,2001$

33. Kawahito S, Maeda T, Motomura T, Ishitoya H, Takano T, Nonaka K, Linneweber J, Ichikawa S, Kawamura M, Hanazaki K, Glueck J, Nosè Y : Hemolytic characteristics of oxygenators during clinical extracorporeal membrane oxygenation. ASAIO Journal 48: 636-639, 2002

34. Kawahito S, Motomura T, Glueck J, Nosé Y : Development of a new hollow fiber silicone membrane oxygenator for ECMO : The recent progress. Ann Thorac Cardiovasc Surg 8:268-274, 2002

35. Kawahito S, Kitahata H, Oshita S : Problems associated with glucose toxicity : role of hyperglycemia-induced oxidative stress. World J Gastroenterol 15 : 4137-4142, 2009

36. Kuntschen FR, Galletti PM, Hahn C : Glucose-insulin interactions during cardiopulmonary bypass. Hypothermia versus normothermia. J Thorac cardiovasc Surg 91 : 451-459,
1986

37. Lehot JJ, Piriz H, Villard J, Cohen R, Guidollet J : Glucose homeostasis. Comparison between hypothermic and normothermic cardiopulmonary bypass. Chest $102: 106-111,1992$

38. Kawahito S, Kitahata H, Kitagawa T, Oshita S : Intensive insulin therapy during cardiovascular surgery. J Med Invest $57: 191-204,2010$

39. Kawahito S, Higuchi S, Mita N, Kitagawa T, Kitahata $\mathrm{H}$ : Novel blood sampling method of an artificial endocrine pancreas via the cardiopulmonary bypass circuit. J Artif Organs 16: 508-509, 2013

40. Kawahito S, Mita N, Soga T, Yagi S, Kakuta N, Satomi S, Kinoshita H, Takaishi K, Kitagawa T, Kitahata H : Accuracy and reliability of continuous blood glucose monitoring during pediatric cardiopulmonary bypass. J Artif Organs $22: 353-356,2019$ 